\title{
Immunochemical Characterization of Variant Medium-Chain Acyl-CoA Dehydrogenase in Fibroblasts from Patients with Medium-Chain Acyl-CoA Dehydrogenase Deficiency
}

\author{
PAUL M. COATES, YASUHIRO INDO, DENISE YOUNG, DANIEL E. HALE, AND KAY TANAKA \\ Divisions of Gastroenterology/Nutrition [P.M.C., D.Y.] and Endocrinology/Diabetes [D.E.H.], The Children's \\ Hospital of Philadelphia, and Department of Pediatrics, University of Pennsylvania School of Medicine, \\ Philadelphia, Pennsylvania 19104; and Department of Human Genetics, Yale University School of Medicine,
} New Haven, Connecticut 06510 [Y.I., K.T.]

\begin{abstract}
Medium-chain acyl-CoA dehydrogenase (MCAD) deficiency is a common autosomal recessive disorder of mitochondrial fatty acid oxidation characterized by episodes of hypoketotic hypoglycemia usually beginning in the first 2 y of life. We previously showed, in pulse labeling experiments, that the biosynthesis and immediate posttranslational processing of MCAD are normal in fibroblasts from patients with MCAD deficiency. Most patients studied to date are homozygous for a point mutation $\left(\mathrm{A}_{985}-\right.$ $G)$ that results in the substitution of glutamate for lysine at residue 304 of the mature MCAD subunit. We performed immunoblot analysis of fibroblast MCAD from a total of 34 patients with MCAD deficiency, including 31 homozygous for the $A_{985}-G$ mutation, using a rabbit antirat MCAD antibody that cross-reacted specifically with human MCAD, but not with the related enzymes, shortchain and long-chain acyl-CoA dehydrogenases. All patients with the $A_{985}-G$ mutation lacked detectable MCAD. Pulse-chase labeling of MCAD-deficient fibroblasts with ${ }^{35} \mathrm{~S}$-methionine demonstrated that this variant $\mathrm{MCAD}$ was unstable compared to controls. Taken together, these data suggest that this mutation affects the stability of MCAD protein within the mitochondrial matrix. (Pediatr Res 31: 34-38, 1992)
\end{abstract}

\section{Abbreviations}

CRM, cross-reacting material

LCAD, long-chain acyl-CoA dehydrogenase

MCAD, medium-chain acyl-CoA dehydrogenase

pMCAD, precursor MCAD

SCAD, short-chain acyl-CoA dehydrogenase

MCAD deficiency is an autosomal recessive disorder of mitochondrial fatty acid oxidation associated with episodes of hypoketotic hypoglycemia, usually beginning in the first 2 y of life. Since its first description in 1982-1983 (1-3), more than 100 cases of MCAD deficiency have been reported, with a clinical phenotype that ranges from completely asymptomatic to an acute episode resulting in sudden infant death; its incidence may

Received July 16, 1990; accepted August 22, 1991.

Correspondence: Paul M. Coates, PhD., Division of Gastroenterology and Nutrition, The Children's Hospital of Philadelphia, 34th Street and Civic Center Blvd., Philadelphia, PA 19104.

Supported by Grants NS17752 and DK38154 from the National Institutes of Health, and Grant 1-1230 from the March of Dimes-Birth Defects Foundation. be as high as 1 in 10000 births among Caucasians (4). MCAD is a homotetrameric flavoenzyme that catalyzes the first step in the mitochondrial oxidation of medium-chain fatty acyl-CoA (6-12 carbon chain length) and is encoded by a nuclear gene on the short arm of chromosome 1 (5). In both rat and human tissues, translation of pMCAD subunits occurs on cytoplasmic ribosomes, followed by mitochondrial uptake and cleavage of the N-terminal leader peptide to yield mature MCAD subunits $(6,7)$. After the addition of flavin adenine dinucleotide (1 equivalent per subunit), they are assembled into the enzymatically active tetramers.

We have previously demonstrated in short-term ( $1 \mathrm{~h})$ labeling experiments with ${ }^{35} \mathrm{~S}$-methionine (7) that fibroblasts from 13 patients with MCAD deficiency synthesized a variant pMCAD subunit of normal size $(46.5 \mathrm{kD})$ and intensity. This subunit was processed to a mature intramitochondrial subunit of normal size $(43.5 \mathrm{kD})$ in amounts comparable to those seen in control fibroblasts. These data implied that variant MCAD in these fibroblasts probably contains a point mutation, but that at least the early steps in its biosynthesis and mitochondrial import proceed normally.

The coding region of human MCAD cDNA is $1263 \mathrm{bp}$ in length and encodes the 421-amino acid pMCAD subunit (8). The amino terminus of the mature human MCAD subunit is currently unknown, but assuming that it is Lys-26, as in the case of rat MCAD (9), the first 25 amino acids constitute the leader peptide. Several laboratories $(10-14)$ recently have reported in cells from numerous MCAD-deficient patients a single prevalent mutation, an $A$ to $G$ transition at position 985 ( $\mathrm{A}_{985}-\mathrm{G}$ ) of the coding region. This mutation results in a lysine-to-glutamate substitution at residue 329 of the precursor MCAD subunit, corresponding to residue 304 of the mature MCAD subunit. To date, this mutation has been reported to account for about $90 \%$ of MCAD-deficient alleles, indicating an unusually high prevalence of this point mutation.

To elucidate the biologic consequences of this mutation, we used immunoblot analysis and pulse-chase (metabolic) labeling of variant MCAD with ${ }^{35} \mathrm{~S}$-methionine in cultured fibroblasts from patients with MCAD deficiency, most of whom were homozygous for the prevalent mutation. For these experiments, we used rabbit antibodies raised against rat liver MCAD and SCAD, which were previously demonstrated to have high affinity and specificity for their human counterparts (15).

\section{MATERIALS AND METHODS}

Materials. Purification of MCAD and SCAD from rat liver, and the preparation of rabbit anti-MCAD and anti-SCAD anti- 
bodies have been described previously (16). Tissue culture materials were obtained from GIBCO (Grand Island, NY).

Fibroblast cultures. Cell cultures were obtained from 34 MCAD-deficient patients. The diagnosis of MCAD deficiency was made using octanoyl-CoA in an electron transfer flavoprotein reduction assay (17). Residual MCAD activity in these cultures ranged from 0 to $13 \%$ of the mean of 120 controls. Normal cell cultures for this study (GM05565, GM05659, GM00038A) were from the Human Genetic Mutant Cell Repository (Camden, NJ). Disease control cultures included two from patients with LCAD deficiency, one from a patient with SCAD deficiency, and one from a patient with a carnitine transport defect.

Skin fibroblasts were grown in Eagle's minimal essential medium supplemented with $10 \% \mathrm{FCS}$ in a $\mathrm{CO}_{2}$ incubator at $37^{\circ} \mathrm{C}$. Confluent monolayers in two $150-\mathrm{cm}^{2}$ flasks were washed twice with PBS, pH 7.4, and harvested with a plastic scraper. The cell pellets were washed twice with PBS by centrifugation at 1500 $\mathrm{rpm}$, collected in a microcentrifuge tube, and stored at $-70^{\circ} \mathrm{C}$. Under these conditions, immunoreactive proteins were stable for at least $6 \mathrm{mo}$, but the samples usually were used within $2 \mathrm{wk}$.

Extraction of cell protein. Cell pellets were thawed and extracted by incubating on ice for $30 \mathrm{~min}$ with $0.3 \mathrm{~mL}$ of extraction buffer containing $50 \mathrm{mM}$ Tris- $\mathrm{HCl}, \mathrm{pH} 7.4 ; 150 \mathrm{mM} \mathrm{NaCl} ; 5$ mM EDTA; $0.02 \%$ sodium azide; $0.5 \%$ Nonidet P-40; and 1 $\mathrm{mM}$ phenylmethylsulfonyl fluoride. Protein content was measured (18) and was adjusted to $2.0 \mathrm{mg} / \mathrm{mL}$ with extraction buffer.

SDS-PAGE and immunoblot analysis. Electrophoresis was carried out on $10 \%$ polyacrylamide slab gels with a $5 \%$ stacking gel, using the discontinuous buffer system of Laemmli (19). One to $10 \mathrm{ng}$ purified rat liver MCAD (in extraction buffer containing BSA at a concentration of $1 \mathrm{mg} / \mathrm{mL}$ to avoid the loss of antigen as a result of adsorption) was used as a standard on each gel. Fibroblast extracts were diluted 1:1 with sample buffer containing: $125 \mathrm{mM}$ Tris- $\mathrm{HCl}, \mathrm{pH} 6.8 ; 4 \%$ SDS; $20 \%$ glycerol; $10 \% 2-$ mercaptoethanol; and $0.005 \%$ bromphenol blue. Aliquots containing $100 \mu \mathrm{g}$ cell protein were applied to the gel in most experiments. In some experiments, protein content applied to the gel was varied from 6 to $300 \mu \mathrm{g} / 100 \mu \mathrm{L}$. In all cases, the final volume applied was $100 \mu \mathrm{L}$; extraction buffer was varied, with sample buffer volume remaining constant.

After electrophoresis, gels were electroblotted (Transblot SD Apparatus; Bio-Rad Laboratories, Richmond, CA) to Immobilon-P membranes (Millipore, Bedford, MA). Membranes were treated as previously described (20), except that incubation with rabbit anti-rat liver MCAD or anti-rat liver SCAD antibody was for $1 \mathrm{~h}$. The antigen/antibody complex was detected using the alkaline phosphatase-conjugated anti-rabbit IgG system (BioRad Laboratories).

Metabolic labeling with ${ }^{35} S$-methionine. This was performed exactly as described by Naito et al. (21) for the labeling of mutant SCAD-deficient fibroblasts. Briefly, cells were exposed to medium containing $100 \mu \mathrm{Ci}{ }^{35} \mathrm{~S}$-methionine for $1 \mathrm{~h}$, followed by incubation with Eagle's minimal essential medium containing $15 \mathrm{mg} / \mathrm{L}$ unlabeled methionine for periods up to $24 \mathrm{~h}$. MCAD was precipitated with anti-rat liver MCAD antibody, washed 10 times, and then electrophoresed using the Laemmli buffer system (19). ${ }^{35}$ S-labeled proteins were detected by fluorography.

Molecular analysis of MCAD mutations. This was performed as previously described (10). Fibroblasts from all 34 patients were analyzed. They included 31 in whom the $A_{985}-G$ transition was the only mutation identified (10; Yokota I, Coates PM, Hale $\mathrm{DE}$, Tanaka $\mathrm{K}$, unpublished observations); one who was heterozygous for $\mathrm{A}_{985} \mathrm{G}$ - and a rare second mutation causing a 13-bp tandem repeat insertion from position 999 in the MCAD cDNA sequence, which leads to a premature chain-terminating codon at the $5^{\prime}$-end of the second repeat $(10,22)$; and two previously unpublished, unrelated patients heterozygous for $\mathrm{A}_{985}-\mathrm{G}$ and an as-yet-unidentified second mutation (Yokota I, Coates PM, Hale DE, Tanaka K, unpublished observations).
RESULTS

Immunoblot analysis of $M C A D$ in fibroblasts from controls and from patients with MCAD deficiency. Among seven controls (three normal, two LCAD-deficient, one SCAD-deficient, and one with a carnitine transport defect), the MCAD band detected by immunoblot analysis was of predicted size (estimated as 45 $\mathrm{kD}$ by SDS-PAGE) and of comparable intensity. Among patients with MCAD deficiency due to the $A_{985}-G$ defect, there was either no MCAD band or a barely detectable band in the region corresponding to MCAD. Typical results are shown in Figure 1. There are other bands with lower or higher apparent molecular weight than MCAD that can be seen in these gels. These bands are of variable intensity and can be seen in all cells, regardless of whether MCAD is present or not. Particularly, there are a few nonspecific bands in the vicinity of the MCAD band, making the results appear somewhat ambiguous. However, these nonspecific bands are much less intense than the MCAD band in controls, and their exact location differs from that of the MCAD band. Therefore, it is possible to judge whether the MCAD band is absent or a faint one is present in the MCAD-deficient cells. When membranes were incubated with rabbit preimmune serum (instead of anti-MCAD antiserum), no bands were observed.

A total of 34 patients with MCAD deficiency have now been studied, all of whom correspond to this pattern, namely no CRM, or at most a very faint band, detectable by immunoblot analysis. Cells from heterozygous parents of these patients demonstrate a prominent band of MCAD protein that is indistinguishable from controls (data not shown).

An experiment was performed to determine the detectable range of MCAD protein in control fibroblasts (Fig. 2). Although gels generally were run with $100 \mu \mathrm{g}$ of cell protein, the antiMCAD antibody could detect MCAD in control cells when as little as $12.5 \mu \mathrm{g}$ of cell protein were applied to the gel. By contrast, there was no increase in detectable MCAD in MCAD-deficient cells, even when as much as $300 \mu \mathrm{g}$ of cell protein were applied to the gel.

Metabolic labeling of MCAD with ${ }^{35} S$-methionine. Cells from a control and from patient no. 574 with MCAD deficiency, homozygous for $\mathrm{A}_{985}-\mathrm{G}$ and lacking a detectable band of MCAD protein by immunoblot analysis, were labeled with ${ }^{35} \mathrm{~S}$-methionine for $1 \mathrm{~h}$ and then exposed to unlabeled methionine for $24 \mathrm{~h}$. Control cells had a single immunoprecipitable band that was stable for $24 \mathrm{~h}$. By contrast, cells from the patient had a very prominent MCAD band after $1 \mathrm{~h}$ of pulse, but the MCAD band had diminished in intensity after $6 \mathrm{~h}$ and had virtually disappeared after $24 \mathrm{~h}$ of exposure to unlabeled methionine (Fig. 3).

Immunoblot analysis of SCAD in fibroblasts from controls and from patients with MCAD deficiency. All patients with MCAD deficiency, as well as all controls, had a readily detectable SCAD band when immunoblot analysis was done using anti-SCAD antibody (Fig. 4).

\section{DISCUSSION}

The results presented here demonstrate a remarkable feature of variant MCAD in the inherited disorder MCAD deficiency. Despite normal translation and immediate posttranslational processing of MCAD in MCAD-deficient fibroblasts (7), virtually no variant MCAD protein is detectable in the steady state, suggesting that the variant MCAD protein within mitochondria in these cells is highly unstable. Thirty-one of the fibroblast cultures were from MCAD-deficient patients homozygous for a single, identical point mutation, $A_{985}-G(10$; Yokota I, Indo $Y$, Coates PM, and Tanaka K, unpublished observations). The present data suggest that this mutation affects the stability of MCAD protein within the mitochondrial matrix. The data suggesting that variant MCAD is unstable are supported by the metabolic labeling experiments using ${ }^{35} \mathrm{~S}$-methionine in Figure 3 , which show that variant MCAD protein disappears almost completely after $24 \mathrm{~h}$ of incubation with unlabeled methionine. 


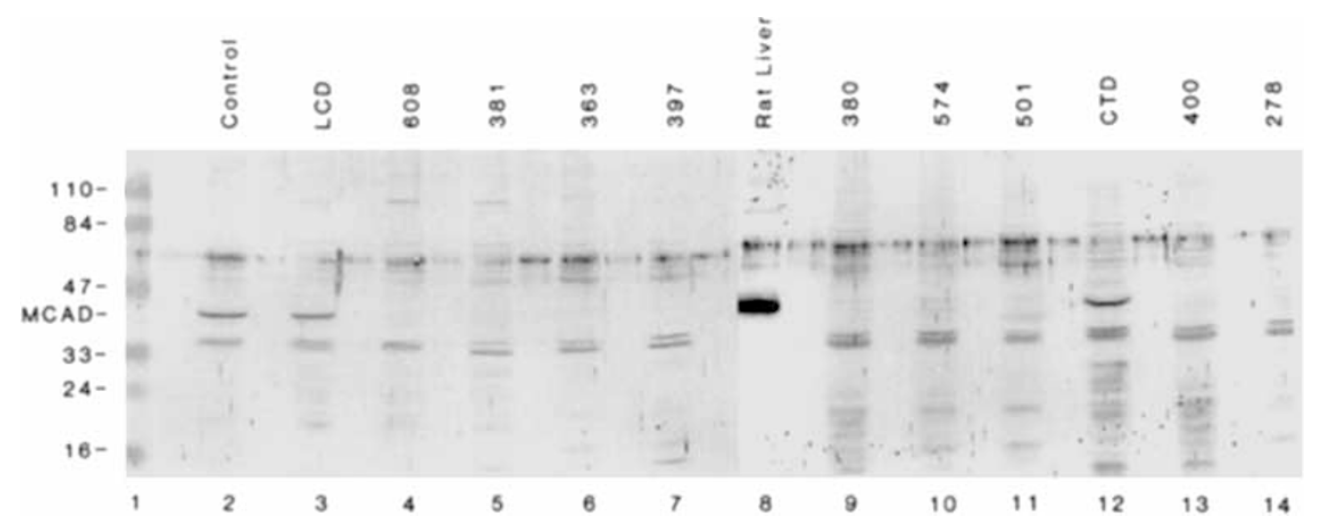

Fig. 1. Immunoblot analysis of MCAD in skin fibroblasts from patients with MCAD deficiency. Lane 1: molecular weight markers (in $\mathrm{kD}$ ). Lane 8: $10 \mathrm{ng}$ purified rat liver MCAD. Lanes 2, 3, and 12: fibroblasts from a control subject, a patient with LCAD deficiency ( $L C A D)$, and a patient with carnitine transport defect (CTD), respectively. Lanes 4-7,9-11,13, and 14: fibroblasts from patients with MCAD deficiency. One hundred $\mu \mathrm{g}$ of cell protein were applied to each lane.
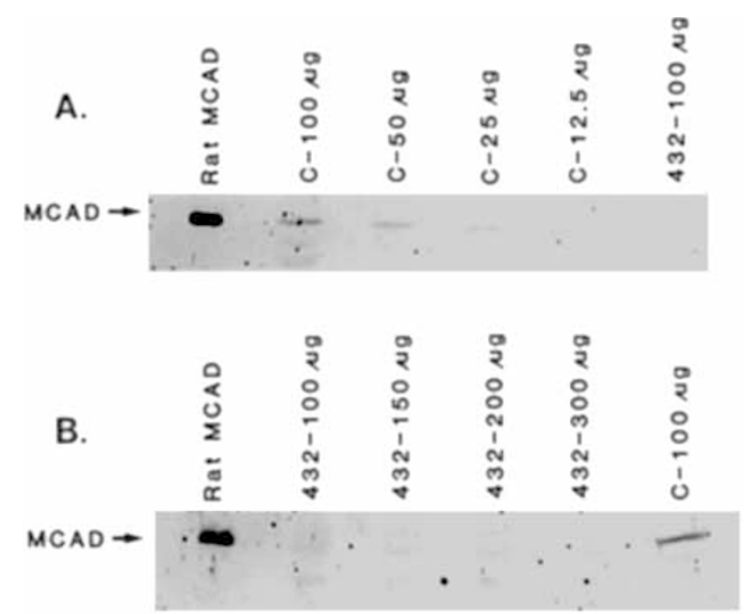

Fig. 2. Detectability of MCAD by immunoblot analysis. $A$, Lane 1 : $1 \mathrm{ng}$ purified rat liver MCAD. Lanes 2-5: control GM05659 at protein concentrations ranging from 100 to $12.5 \mu \mathrm{g} /$ lane. Lane 6: patient $\mathrm{CP}$ $432(100 \mu \mathrm{g}) . B$, Lane $1: 1 \mathrm{ng}$ purified rat liver MCAD. Lanes 2-5: patient $\mathrm{CP} 432$ at protein concentrations ranging from 100 to $300 \mu \mathrm{g}$ per lane. Lane 6: control GM05659, $100 \mu \mathrm{g}$.

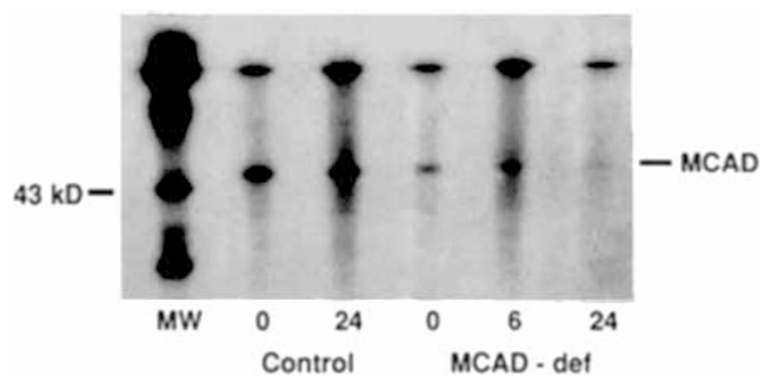

Fig. 3. Metabolic labeling of MCAD. SDS-PAGE of fibroblast MCAD after ${ }^{35} \mathrm{~S}$-methionine labeling and immunoprecipitation with anti-rat liver MCAD. Lane 1: ${ }^{14} \mathrm{C}$-labeled molecular weight markers. Lanes 2-3: control cells incubated with $100 \mu \mathrm{Ci}^{35} \mathrm{~S}$-methionine for $1 \mathrm{~h}$, then with unlabeled methionine for 0 and $24 \mathrm{~h}$, respectively. Lanes 4-6: A985G homozygous MCAD-deficient cells incubated with $100 \mu \mathrm{Ci}{ }^{35} \mathrm{~S}$ methionine for $1 \mathrm{~h}$, then with unlabeled methionine for 0,6 , and $24 \mathrm{~h}$, respectively.

The absence of a variant MCAD band is not due to decreased viability of MCAD-deficient cells, inasmuch as they contain a readily detectable SCAD band by immunoblot analysis.

Inagaki et al. (23) demonstrated that fibroblasts from one patient with MCAD deficiency (patient MV) had no detectable
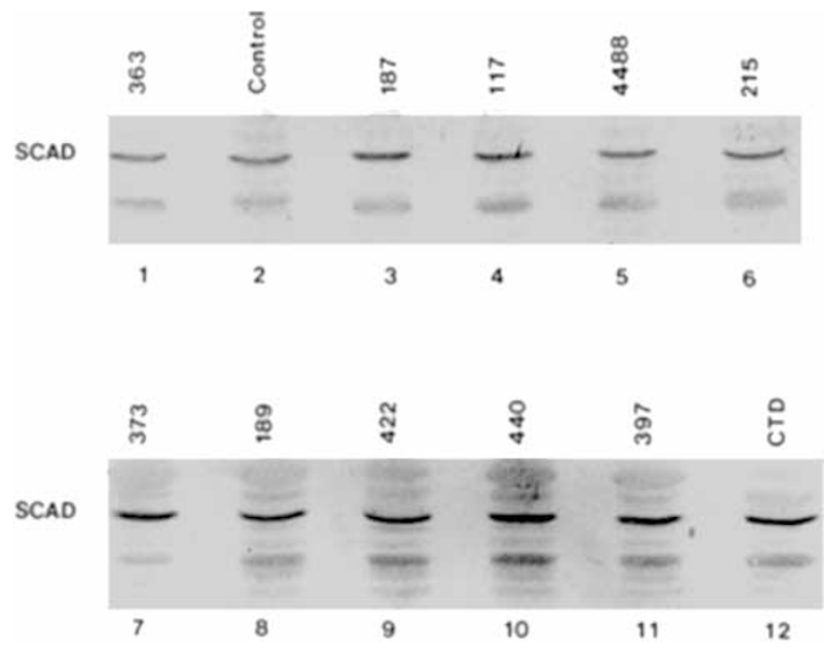

Fig. 4. Immunoblot analysis of SCAD in skin fibroblasts from patients with MCAD deficiency. Lanes 1 and 3-10: fibroblasts from patients with MCAD deficiency. Lanes 2 and 12: fibroblasts from control and carnitine transport defect $(C T D)$ patients, respectively. One hundred $\mu \mathrm{g}$ of cell protein were applied to each lane.

band of MCAD protein by immunoblot analysis. This patient is the same one as our patient no. 363 (Fig. 1) with confirmed MCAD deficiency (24), and who is homozygous for the $A_{985}-G$ mutation (Yokota I, Coates PM, Hale DE, Tanaka K, unpublished observations). Our data confirm the findings of Inagaki et al. in this patient. Their other patient, AH, had a detectable MCAD protein band by immunoblot analysis; it seems likely that this patient has another mutation that does not affect MCAD stability.

Several mechanisms to explain the instability of the variant MCAD product of the $A_{985}-G$ mutant allele are possible. These include inherent instability of the variant subunit and inhibition of intramitochondrial processing that occurs after cleavage of the leader peptide; the latter could be inhibition at the level of conformational changes via the action of chaperone proteins (25) or inhibition of tetramer formation. We previously noted that computer analysis predicted that the Lys-304 to Glu substitution would not cause drastic changes in the secondary structure of MCAD (10). Residue 304 is located in a domain that is not thought to be involved in flavin adenine dinucleotide binding or in substrate binding (26), but instead may form the interface in the tetramer structure. It is an attractive hypothesis that substitution of a basic residue in this region with an acidic one may hinder tetramer formation or disrupt normal tetramer structure $(10,12,13)$. 
Our data, and those of Inagaki et al. (23) in patient MV, disagree with the results reported by Strauss et al. (27), who demonstrated that variant MCAD in fibroblasts from four other unrelated patients with MCAD deficiency was readily detectable by immunoblot analysis. Furthermore, fibroblasts from three affected members of another family (28) had an immunoreactive MCAD band (13). All seven of these patients were reported to be homozygous for the $\mathrm{A}_{985}-\mathrm{G}$ mutation. On the other hand, MCAD was virtually absent by immunoblot analysis of liver (13) from the proband in the same family, which led these authors to suggest that the variant MCAD protein is unstable in vivo. We have no immediate explanation for the discrepancy between our immunoblot findings and those of Kelly et al. (13); perhaps there are technical variations in the preparation of samples for immunoblot analysis that might account for the difference. We also considered that there might be a difference in the anti-MCAD antibodies that we and they have used in immunoblot experiments. This was ruled out, however, when we performed studies using both anti-rat liver and anti-pig kidney antibodies, which gave qualitatively similar results (data not shown).

Among the 34 MCAD-deficient patients whom we have studied here, three were compound heterozygotes for the $A_{985}-G$ transition and another variant MCAD allele. The finding that cells from patient no. 215 , a compound heterozygote, are also CRM-negative appears to be consistent with the molecular analysis of his defect. One of his MCAD alleles carries the $\mathrm{A}_{985}-\mathrm{G}$ transition, and the other contains a 13-bp tandem repeat from position 999 , which results in a premature termination codon at the end of the second repeat $(10,22)$. When the X-ray from the previous ${ }^{35} \mathrm{~S}$-methionine pulse labeling experiment with patient no. 215 (7) was reexamined, there was no evidence of a truncated variant MCAD band. These observations in cells from patient no. 215 are consistent with the results of polymerase chain reaction amplification, indicating that the variant allele with the 13-bp repeat is not well expressed. When polymerase chain reaction was performed using genomic DNA as template, the intensities of the two bands on agarose gels were always equal. On the other hand, when cDNA was used as template, the higher molecular weight band (containing the 13-bp repeat) was much weaker than the band containing $\mathrm{A}_{985} \mathrm{G}$, suggesting inefficient transcription or instability of mRNA $(10,22)$. The second variant allele in the other two patients remains to be identified.

The homogeneous immunoblot data that we have obtained from patients with MCAD deficiency (all CRM-negative) stand in sharp contrast to those obtained for variant enzymes in patients with other acyl-CoA dehydrogenase deficiencies. Among three patients with SCAD deficiency, variant SCAD was of normal size when tested by ${ }^{35} \mathrm{~S}$-methionine labeling and immunoprecipitation (21). However, when examined by immunoblot analysis, one was CRM-negative and two were CRM-positive. Subsequent sequence analysis of the CRM-negative SCAD-deficient cells (29) demonstrated two distinct mutant alleles, each encoding a different point mutation; neither mutation was observed in the other two SCAD-deficient cultures. Among 15 patients with isovaleric acidemia, at least five distinct types of variant alleles were identified, some of which were associated with immunoreactive variant isovaleryl-CoA dehydrogenase of normal or truncated size and some of which resulted in no immunoreactive protein (30). Among nine patients with LCAD deficiency, variant LCAD was present (CRM-positive) and of comparable size and quantity to LCAD in control fibroblasts (31).

Acknowledgments. Rat liver MCAD and anti-rat liver MCAD and anti-rat liver SCAD antibodies used in these studies were prepared by Dr. Yasuyuki Ikeda. The authors thank Dr. Arnold Strauss for generously providing anti-pig kidney MCAD antibody for some of these studies.

\section{REFERENCES}

1. Kolvraa S, Gregersen N, Christensen E, Hobolth N 1982 In vitro fibroblast studies in a patient with $\mathrm{C}_{6}-\mathrm{C}_{10}$-dicarboxylic aciduria: evidence for a defect in general acyl-CoA dehydrogenase. Clin Chim Acta 126:53-67

2. Stanley CA, Hale DE, Coates PM, Hall CL, Corkey BE, Yang W, Kelley RI, Gonzales EL, Williamson JR, Baker L 1983 Medium-chain acyl-CoA dehydrogenase deficiency in children with non-ketotic hypoglycemia and low carnitine levels. Pediatr Res 17:877-884

3. Rhead WJ, Amendt BA, Fritchman KS, Felts SJ 1983 Dicarboxylic aciduria: deficient $\left[1-{ }^{14} \mathrm{C}\right]$ octanoate oxidation and medium-chain acyl-CoA dehydrogenase in fibroblasts. Science 221:73-75

4. Roe CR, Coates PM 1989 Acyl-CoA dehydrogenase deficiencies. In: Scriver CR, Beaudet AL, Sly WS, Valle D (eds) The Metabolic Basis of Inherited Disease. McGraw Hill, New York, pp 889-914

5. Matsubara Y, Kraus JP, Yang-Feng TL, Francke U, Rosenberg LE, Tanaka K 1986 Molecular cloning of cDNAs encoding rat and human medium-chain acyl-CoA dehydrogenase and assignment of the gene to human chromosome 1. Proc Natl Acad Sci USA 83:6543-6547

6. Ikeda Y, Keese SM, Fenton WA, Tanaka K 1987 Biosynthesis of rat liver mitochondrial short chain acyl-CoA, medium chain acyl-CoA, long chain acyl-CoA, and isovaleryl-CoA dehydrogenases: in vitro synthesis, import into mitochondria, and processing of their precursors in a cell-free system and in cultured cells. Arch Biochem Biophys 252:662-674

7. Ikeda Y, Hale DE, Keese SM, Coates PM, Tanaka K 1986 Biosynthesis of variant medium chain acyl-CoA dehydrogenase in cultured fibroblasts from patients with medium chain acyl-CoA dehydrogenase deficiency. Pediatr Res 20:843-847

8. Kelly DP, Kim J-J, Billadello JJ, Hainline BE, Chu TW, Strauss AW 1987 Nucleotide sequence of medium-chain acyl-CoA dehydrogenase mRNA and its expression in enzyme-deficient human tissue. Proc Natl Acad Sci USA 84:4068-4072

9. Matsubara Y, Kraus JP, Ozasa H, Glassberg R, Finocchiaro G, Ikeda Y, Mole $J$, Rosenberg LE, Tanaka K 1987 Molecular cloning and nucleotide sequence of cDNA encoding the entire precursor of rat liver medium chain acyl coenzyme A dehydrogenase. J Biol Chem 262:10104-10108

10. Yokota I, Indo Y, Coates PM. Tanaka K 1990 The molecular basis of mediumchain acyl-coenzyme $A$ dehydrogenase deficiency: an $A$ to $G$ transition at position 985 that causes a lysine-304 to glutamate substitution in the mature protein is the single prevalent mutation. J Clin Invest 86:1000-1003

11. Matsubara Y, Narisawa K, Miyabayashi S, Tada K. Coates PM, Bachmann C, Elsas LJ, Pollitt RJ, Rhead WJ, Roe CR 1990 Identification of a common mutation in patients with medium-chain acyl-CoA dehydrogenase deficiency. Biochem Biophys Res Commun 171:498-505

12. Gregersen N, Andresen BS, Bross P, Winter V, Rudiger N, Engst S, Christensen E, Kelly D, Strauss AW, Kolvraa S, Bolund L, Ghisla S 1991 Molecular characterization of medium-chain acyl-CoA dehydrogenase (MCAD) deficiency: identification of a lys ${ }^{329}$ to glu mutation in the MCAD gene, and expression of inactive mutant enzyme protein in E. coli. Hum Genet 86:545551

13. Kelly DP, Whelan AJ, Ogden ML, Alpers R, Zhang Z, Bellus G, Gregersen N, Dorland L, Strauss AW 1990 Molecular characterization of inherited medium-chain acyl-CoA dehydrogenase deficiency. Proc Natl Acad Sci USA 97:9326-9240

14. Ding J-H, Roe CR, Chen Y-T, Matsubara Y, Narisawa K 1990 Mutations in medium chain acyl-CoA dehydrogenase deficiency. Lancet 336:748-749

15. Ikeda Y, Tanaka K 1987 Immunoprecipitation and electrophoretic analysis of four human acyl-CoA dehydrogenases and electron transfer flavoprotein using antibodies raised against the corresponding rat enzymes. Biochem Med Metab Biol 37:329-334

16. Ikeda Y, Okamura-Ikeda K, Tanaka K 1985 Purification and characterization of short-chain, medium-chain and long-chain acyl-CoA dehydrogenases from rat liver mitochondria: isolation of the holo- and apoenzymes and conversion of the apoenzyme to the holoenzyme. J Biol Chem 260:1311-1325

17. Hale DE, Stanley CA, Coates PM 1990 Genetic defects of acyl-CoA dehydrogenases: studies using an electron transfer flavoprotein reduction assay. In: Tanaka K, Coates PM (eds) Fatty Acid Oxidation: Clinical, Biochemical, and Molecular Aspects. Alan R Liss Inc, New York, pp 333-348

18. Smith PK, Krohn RI, Hermanson GT, Mallia AK, Gartner FH, Provenzano MD, Fujimoto EK, Goeke NM, Olson BJ, Klenk DC 1985 Measurement of protein using bicinchoninic acid. Anal Biochem 150:76-85

19. Laemmli UK 1970 Cleavage of structural proteins during the assembly of the head of bacteriophage T4. Nature 227:680-685

20. Indo Y, Kitano A, Endo F, Akaboshi I, Matsuda I 1987 Altered kinetic properties of the branched-chain alpha-keto acid dehydrogenase complex due to mutation of the beta-subunit of the branched chain alpha-keto decarboxylase $\left(E_{1}\right)$ component in lymphoblastoid cells derived from patients with maple syrup urine disease. J Clin Invest 80:63-70

21. Naito E, Indo Y Tanaka K 1989 Short chain acyl-coenzyme A dehydrogenase (SCAD) deficiency: immunochemical demonstration of molecular heterogeneity due to variant SCAD with differing stability. J Clin Invest 84:16711674

22. Yokota I, Tanaka K Coates PM, Ugarte M 1990 Mutations in medium chain acyl-CoA dehydrogenase deficiency. Lancet 336:748

23. Inagaki $T$, Ohishi $N$, Bachmann $C$, Ghisla $S$, Tsukagoshi $N$, Udaka S, Yagi $K$ $1990 \mathrm{Imm}$ unochemical and molecular analysis of medium-chain acyl COA dehydrogenase deficiency. J Clin Biochem Nutr 8:1-8

24. Catzeflis C, Bachmann C, Hale DE, Coates PM, Wiesmann U, Colombo JP, 
Joris F, Deleze G 1990 Early diagnosis and treatment of neonatal mediumchain acyl-CoA dehydrogenase deficiency. Eur J Pediatr 149:577-581

25. Cheng MY, Hartl F-U, Martin J, Pollock RA, Kalousek F, Neupert W, Hallberg

EM, Hallberg FL, Horwich AL 1989 Mitochondrial heat-shock protein hsp60 is essential for assembly of proteins imported into yeast mitochondria. Nature $337: 620-625$

26. Kim J-JP, Wu J 1988 Structure of medium-chain acyl-CoA dehydrogenase from pig liver mitochondria at 3-A resolution. Proc Natl Acad Sci USA 85:6677-6681

27. Strauss AW, Duran M, Zhang Z, Alpers R, Kelly DP 1990 Molecular analysis of medium chain acyl-CoA dehydrogenase deficiency. In: Tanaka K, Coates PM (eds) Fatty Acid Oxidation: Clinical, Biochemical, and Molecular Aspects. Alan R Liss Inc, New York, pp 609-623
28. Duran M, Hofkamp M, Rhead WJ, Saudubray J-M, Wadman SK 1986 Sudden child death and "healthy" affected members with medium-chain acyl-coenzyme A dehydrogenase deficiency. Pediatrics 78:1052-1057

29. Naito E, Indo Y, Tanaka K 1990 Identification of two variant short chain acyl-coenzyme A dehydrogenase alleles, each containing a different point mutation in a patient with short chain acyl-coenzyme A dehydrogenase deficiency. J Clin Invest 85:1575-1582

30. Ikeda Y, Keese SM, Tanaka K 1985 Molecular heterogeneity of variant isovaleryl-CoA dehydrogenase from cultured isovaleric acidemia fibroblasts. Proc Natl Acad Sci USA 82:7081m7085

31. Indo $Y$, Coates PM, Hale DE, Tanaka K 1991 Immunochemical characterization of variant long-chain acyl-CoA dehydrogenase in cultured fibroblasts from nine patients with long-chain acyl-CoA dehydrogenase deficiency. Pediatr Res 30:211-215

\section{Announcements}

\section{Call for Abstracts}

The Society for Behavioral Pediatrics will conduct its 10th Annual Scientific meeting on September 20-21, 1992 at the Hyatt Regency Hotel in St. Louis, MO. We invite you to submit abstracts of research papers for consideration for presentation at the scientific sessions. Abstracts must be received by March 1, 1992. For further information and abstract forms, please contact Ms. Noreen Spota at (215) 248-9168.

\section{Fifth International Pediatric Surgical Research Workshop}

The Fifth International Pediatric Surgical Research Workshop will be held May 29, 1992 in Ferrara, Italy. For further information, contact: Dott. Andrea Franchella, Chirurgia Pediatrica, Arcispedale S. Anna, 44100 Ferrara, Italy, Telephone (39) 532 295580, FAX (39) 532209819. 